\title{
Practical thoughts regarding filtered tailings
}

\author{
B Ulrich Stantec Consulting Services, Inc., USA
}

\begin{abstract}
Filtered tailings technology has been successfully implemented only at a limited number of relatively low-production-rate mining operations. The technology, however, may be poised to make a dramatic leap forward as it is being proposed for use at several high-throughput operations. Demands from increasing regulatory scrutiny and decreasing water availability are likely to drive further adoption of the technology. This paper presents a recommended approach to select a tailings disposal method and summarises several filtered tailings design concepts and considerations that the author has found useful in his practical experience.
\end{abstract}

Keywords: tailings, filtered, trafficability, design

\section{Introduction}

Conventional slurried tailings have been produced as a by-product of mineral processing, and engineering and operational approaches have been developed to engineer a tailings storage facility (TSF) capable of safely storing the tailings. Recently, alternatives to conventional slurried tailings (thickened, paste, and filtered tailings) have been developed and implemented in the mining industry. These alternatives improve the possibility of engineering the properties of the tailings themselves to better address site conditions or limitations.

The tailings continuum has been presented numerous times elsewhere, and simply represents the nature and behaviour of tailings at various degrees of thickening, as follows:

- Conventional slurry tailings.

- Thickened tailings.

- Paste tailings.

- Filter cake.

The delineation between these alternative technologies is often vague with various classification systems and terminology in use. The author has found a performance-oriented classification system based on yield stress, rather than solids content, to be useful.

Yield stress is often employed as a distinct boundary to help define these brackets within the continuum. According to Ulrich and Kerr (2011), the fully shear-thinned yield stress separating conventional slurry tailings and thickened tailings, tend to range between 5 and 20 Pascals $(\mathrm{Pa}$ ) (48 $\mathrm{Pa}$ is approximately 1 pound per square foot (psf)). The boundary between thickened and paste tailings is approximately $100 \mathrm{~Pa}$ and the boundary between paste tailings and filter cake is $800 \mathrm{~Pa}$. This information is summarised in Table 1 .

Table 1 Tailings continuum

\begin{tabular}{lll}
\hline Tailings classification & Yield stress $(\mathrm{Pa}) *$ & Typical solids content (\%) \\
\hline Conventional slurried tailings & $<5$ to 20 & $<50$ \\
Thickened tailings & 20 to 100 & 50 to 70 \\
Paste tailings & 100 to 800 & 70 to 85 \\
Filtered tailings & $>800$ & $>85$ \\
\hline
\end{tabular}

*Yield stress is measured at the point of deposition using a shear vane device. 
The application of filtered tailings technology appears poised to make a dramatic leap forward, moving from use at a limited number of relatively low-production-rate operations (6,000 tonnes per day (tpd) or less) to greater adoption and use at relatively high-production-rate facilities (exceeding 50,000 tpd). Filtered tailings are proposed for use at high production-rate mines such as Nevada Copper's Pumpkin Hollow Project at 70,000 tpd (Nevada Copper Corp 2017) and the planned Metates and Rosemont mines (both with proposed production rates of $90,000 \mathrm{tpd}$ ). Filtered tailings are also currently undergoing proof-of-concept testing for use as part of the EcoTails system at the Peñasquito mine (Hudbay 2017; M3 2016; Mining Magazine 2017). The successful implementation of this technology at one of these projects would represent a significant precedent in the industry.

There are numerous external pressures likely to drive additional implementation of this technology. These include regulatory and internal corporate scrutiny, which is especially heightened in the post-Mt. Polley and Fundao TSF failure environments and the designation of filtered tailings as a best available technology for tailings storage (Independent Expert Engineering Investigation and Review Panel 2015). Another key pressure is increasing water scarcity worldwide, which may intensify concerns regarding a mine's social license to operate if an operation is seen to be competing with local users for water.

\section{Selecting a preferred disposal alternative}

Considering this momentum for the technology, how should practitioners view filtered tailings and how should they select a preferred tailings management solution?

Ulrich and Coffin (2013) wrote that there are no universal remedies for tailings storage and that every tailings facility should be designed based on project-specific requirements. Watson (2010) wrote that alternative tailing disposal practices have been viewed as a silver bullet that will solve all tailings management issues, yet misconceptions abound. Davies (2011) wrote that each project should be assessed for the potential applicability of filtered tailings based upon technical, economical, and regulatory constraints. Upon reflection, the present author is certain that Davies unintentionally left out social considerations from his list.

Davies (2011) continued that filtered tailings are not a panacea for mine waste management and that they should be appropriately viewed as a potential alternative form of tailings placement and a part of the overall tailings continuum of options. Similarly, the 2014 Elko Roundtable (an annual, by-invitation-only event that serves as a forum for the free sharing of industry information, insights and lessons learned. It is held in Elko, Nevada, USA) proceedings stated that:

"...properly designed, constructed and operated filtered tailings facilities may offer the closest application the industry has in attaining a truly walkaway tailings facility. It was noted that there is no one-size-fits-all technology that are suitable for all applications. This statement also applies to filtered tailings. Each project should be approached individually, and technologies chosen, or discarded, based on their merits for the specific site". (Ulrich 2015)

Furthermore, filtered tailings operations can be equally as susceptible to performance challenges as those using other tailings disposal technologies. Wilson and Robertson (2015) alluded to two filtered tailings facilities where "the design, operating and site conditions have [led] to an urgent need for remedial modifications to avoid failure conditions".

There is broad concurrence in the industry that no one technology provides a universal solution for tailings management. There is, however, growing agreement that filtered tailings can offer significant advantages and should nearly always be considered as an option for new tailings storage facilities.

An alternatives assessment should be performed as a part of the development or expansion of tailings storage facilities to aid in the selection of the most appropriate tailings management solution. The assessment should include not only an evaluation of various tailings storage locations, but also various tailings preparation methods, including conventional slurried, thickened, paste and filtered tailings in various storage locations such as surface deposits, surface impoundments, underground workings, and open pits. 
While typically not considered acceptable based on regulatory and corporate policies, the consideration of lake and marine disposal alternatives may also be warranted.

While alternatives are often considered during initial scoping studies, the completion of a more formal alternatives assessment can be valuable. The methodology developed by Environment and Climate Change Canada in their Guidelines for the Assessment of Alternatives for Mine Waste Disposal (the Guidelines) (Environment and Climate Change Canada 2016) is a helpful framework for performing alternatives analyses. The approach presented in the Guidelines includes the identification of all possible mine waste disposal alternatives, a pre-screening stage to remove alternatives with clear fatal flaws, and a quantitative assessment of the remaining alternatives using a Multiple Accounts Analysis (MAA) approach which considers environmental, technical, economic, and socio-economic impacts, building on the method described by Robertson and Shaw (1999).

The identification and consideration of all possible alternatives encourages the designer and owner to think beyond their typical experience and preconceptions for the site, while the MAA methodology facilitates the incorporation of value judgements from various stakeholders regarding the impacts of the alternatives. Even if the assessment is only being completed for internal use, the MAA can incorporate input from the members of the design team and mining company with differing areas of focus and responsibility.

\section{Design considerations}

Selecting the tailings deposition technology is only the first step in implementing the tailings storage solution as next the practitioner will need to develop the overall facility design. The following summarises selected design concepts and considerations that the author has found beneficial in his practical experience.

\subsection{Target moisture content for clayey tailings}

Too often, the operational moisture content of the filter cake is based solely on filter plant production considerations, economics or other drivers, rather than geotechnical requirements. Davies (2011) wrote that one of the most misunderstood design parameters for a filtered tailings operation is the target moisture content for the filter cake. The goal should be to achieve a moisture content that eases construction and meets slope stability criteria. A rule of thumb is to target the moisture content equivalent to the standard Proctor (American Society for Testing and Materials 2012a) optimum moisture content. This is often altered to account for the climate (slightly drier for wetter climates and slightly wetter for drier climates) and for higher-throughput operations where filtered tailings stacks employ larger compaction equipment (where it may be more appropriate to reference the modified Proctor (American Society for Testing and Materials 2012b) optimum moisture content (Davies 2011)).

For higher clay content tailings, the necessary filter plant cycle times and the resulting capital and operating costs to produce a filter cake near the optimum moisture content typically increase significantly and it can be impractical to specify a Proctor-based target moisture content. Thus, for higher clay content tailings (such as those with a saturated hydraulic conductivity of $1 \times 10^{-5}$ centimetres per second $(\mathrm{cm} / \mathrm{s})$ or less), a constructability based target should be considered, where the moisture content is targeted to allow for a trafficable tailings surface. The term 'trafficable' here is used as a general term meaning that mobile equipment can move (traffic) on the surface in the way they are intended.

To achieve a trafficable surface, the filtered tailings should provide adequate bearing capacity for the equipment that will be accessing the filtered tailings. At a scoping level, this can be estimated based on literature relationships and published construction equipment ground pressures, as will be discussed further. 
Based on a database of 641 fall cone test results from 101 cohesive soil samples, Vardanega and Haigh (2014) developed a correlation between the undrained shear strength of a soil $\left(\mathrm{C}_{\mathrm{u}}\right)$ in kilopascals $(\mathrm{kPa})$ and its liquidity index (LI), as follows:

$$
\mathrm{Cu}=1.7 \times 35^{(1-\mathrm{LI})} \mathrm{kPa} \text { for } 0.2<\mathrm{LI}<1.1
$$

where:

$$
L I=(\omega-P L) /(L L-P L)
$$

and:
$\omega=$ moisture content of the soil.
$\mathrm{PL} \quad=$ moisture content at the soil's plastic limit.
$\mathrm{LL} \quad=$ moisture content at the soil's liquid limit.

It follows that:

$$
\begin{array}{ll}
\text { If } \quad \omega=L L \text {, then } L I=1 \\
\text { and if } \quad \omega=P L \text {, then } L I=0 .
\end{array}
$$

Note that Vardanega and Haigh (2014) suggest that their relationship is only applicable to LI values between 0.2 and 1.1 as their dataset below 0.2 is limited and there is considerable curvature in the data above LI values of 1.1 .

Note that the moisture content used in the equations is as defined by a geotechnical engineer (mass of water divided by mass of solids), not as would be defined by a metallurgist (mass of water divided by total mass), which can be a point of confusion, as discussed elsewhere (such as Ulrich \& Coffin 2013).

Figure 1 presents plotted results from Equation 1 for soils with varying LLs and PLs within the range of LI values suggested by Vardanega and Haigh (2014). Two conclusions are immediately obvious:

1. The strength increases significantly for soils as the soil's moisture content is drier than its liquid limit and nearer to its plastic limit.

2. There is significantly greater impact of moisture content on undrained shear strength for soils with a lower plasticity index $(\mathrm{PI}=\mathrm{LL}-\mathrm{PL})$.

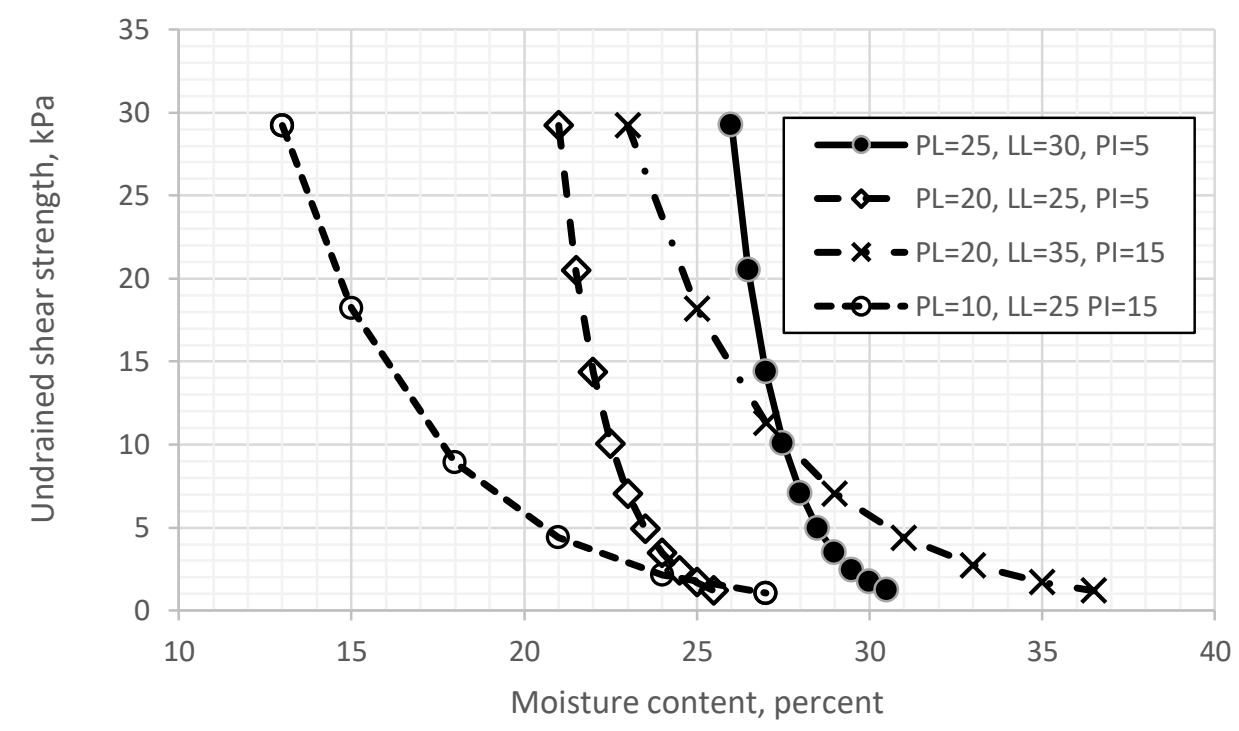

Figure 1 Estimated undrained shear strength results for various moisture content ranges 
Per Equation 1, the undrained shear strength of a soil can be estimated as 60 and $2 \mathrm{kPa}$ when the moisture content is at its PL and LL, respectively. Using Terzaghi's bearing capacity equation for a square footing bearing on a cohesive soil with these strengths (refer to Sivakugan and Das (2010), for example), the ultimate bearing capacity ( $q_{\text {ult }}$ ) is about 260 and $20 \mathrm{kPa}$, when the moisture content is at its PL and LL respectively. Assuming a Factor of Safety of 3 to account for uncertainty (typical for spread footings), these ultimate bearing capacities are reduced to allowable bearing capacities ( $q_{\text {all }}$ ) of about 90 and $7 \mathrm{kPa}$, for a soil at its PL and LL, respectively. This information is summarised in Table 2.

\section{Table 2 Summary of bearing capacities}

\begin{tabular}{llc}
\hline Moisture content & \multicolumn{2}{l}{ Bearing capacity, } \\
& qPa \\
& qult & qall \\
\hline$=\mathrm{PL}$ & 260 & 90 \\
$\omega=\mathrm{LL}$ & 20 & 7 \\
\hline
\end{tabular}

To be trafficable by earthmoving and haulage equipment, the bearing capacity of the filtered tailings should generally be greater than the ground pressure applied by the equipment working on the filter stack surface (although, it is likely possible to traffic areas while some limited amount of bearing capacity failures occur).

Examples of ground pressures are useful for illustration purposes. A typical person walking slowly may exert a ground pressure of about $40 \mathrm{kPa}$. Approximate ground pressures for various earthmoving and haulage equipment (Caterpillar 2012) are as follows:

- D6 low ground pressure dozer $=30 \mathrm{kPa}$.

- $320 \mathrm{D}$ excavator $=40 \mathrm{kPa}$.

- Articulated trucks $=400 \mathrm{kPa}$.

This information should be compared to the information shown in Table 2, to establish whether trafficability will be possible. Whether Terzaghi's bearing capacity equation is entirely applicable for moving equipment is debatable, but the guidance provided by the relationship still holds merit as a rule of thumb. It is considered applicable for initial assessments of the required production moisture content and may be useful guidance in reviewing filter testing results. Adjustments to the target moisture content values may then be made to account for variations in the moisture content, due to conditions at the project site. These include:

- Arid climate: In arid climates, additional drying would occur naturally during transport and placement in the filter stack. For example, significant reductions in moisture content may occur on a long conveyor belt in an arid climate and at operations which use long dozer pushes to spread and place the tailings.

- Wet or cold climate: In wet or cold climates, it may be necessary to decrease the target moisture content, as additional environmental moisture may enter into the filtered tailings during conveyance, transport, and after placement.

Consideration of the material strengths represents a first step in defining the moisture content requirements for clay tailings, and other considerations such as global slope stability criteria or the potential for saturation or seepage may eventually govern the target moisture content selection.

\subsection{Designing to accommodate varying tailings characteristics}

One common difficulty in the operation of filtered tailings stacks is accounting for excessively wet tailings. This may occur because of high intensity precipitation, long duration precipitation (such as during wet seasons), variations in the characteristics of the incoming ore, or operational and maintenance problems with the filtration equipment. Mines using filtered tailings disposal often include a conventional slurried tailings impoundment to allow for emergency deposition of tailings during periods of filter maintenance or when 
significantly out-of-specification filtered tailings are produced. However, limiting tailings deposition into the emergency facility to minimise the facility size and maximise the benefits of filtered tailings is always preferred. As such, designers commonly need to develop a filtered tailings stack design that can accommodate tailings with a wider range of moisture contents.

The most common manner of addressing out-of-specification, or wet season tailings, is to include a defined area in the inner area (zone) of the stack away from the outer perimeter (the structural zone), where these higher moisture content tailings are to be placed. This inner zone may receive limited, or no, mechanical compaction. The zone must be designed to provide environmental protection and to satisfy overall slope stability criteria. Furthermore, in cases where this zone is anticipated to be used for long durations during the wet season, the design should consider material balance requirements to ensure that the zone has sufficient capacity to carry operations through to the end of the season. Consideration should also be given to incorporating decant facilities in this zone, to allow precipitation and bleed water from the tailings to be removed from the facility.

The zoning can be developed using several design approaches, but typical approaches mimic conventional tailings dam designs, in a form of the following:

- Downstream construction: The outer structural filtered tailings are first placed and compacted (if required) in a zone that is similar to a starter dam (or this zone may be constructed of borrow material). Inner tailings are impounded by this dam. The dam is expanded in the downstream direction and sized to accommodate the wet season placement of tailings. Developing staging for this approach requires careful material balance calculations.

- Centreline construction: Similar to the downstream construction approach, but the crest of the dam rises vertically as the facility is expanded.

- Upstream construction: The crest of the dam shifts upstream for raises above a starter dam. The degree of upstream shift may vary, from a significant upstream shift (an upstream raise) to a raise with a reduced upstream shift (sometimes described as modified centreline (Haile \& Brouwer, n.d.)). In either case, while the dam may appear wide, it only comprises a structural shell above the starter dam and relies on the strength of the underlying inner zone tailings to a greater extent than the other two approaches for stability. This method requires more careful consideration of material strengths than the other two approaches and may present higher risks overall.

These types of facilities have been described elsewhere (i.e. Kerr \& Ulrich 2011). There are, of course, several hybrid forms of each of these designs.

\subsection{Loading rate and liquefaction}

Filtered tailings facilities are often referred to informally as dry stacks. This could lead a designer to overlook the possibility of liquefaction or the generation of excess pore pressures during operations. However, as discussed by Ulrich and Coffin (2013), saturation and problematic pore pressures can develop in a dry stack.

The in situ moisture content of the filtered tailings at any point in the stack are a function of the production moisture content, climatic factors, hydraulic conductivity, confining stress, suction, stiffness, and rate of loading. Recall that the optimum moisture content from Proctor testing is often selected as a target moisture content. In many cases, the optimum moisture content is relatively near the zero-air void curve (especially for clayey materials), indicating the relatively proximity to saturation in initially placed conditions. As the stack continues to rise, the air voids are compressed and the moisture content will increase (if the amount of water is not decreasing). Construction-induced loading from subsequent tailings placement can lead to saturation and potentially the formation of excess pore pressures, which can result in slope stability risks and the potential for liquefaction. This is further exacerbated if the filtered tailings are produced at a higher moisture content than was assumed in the design. 
The loading rate should be considered in the facility design and may require the construction of a facility with a larger footprint area to reduce the rate of loading. If zones of saturated tailings may occur, and the potential for liquefaction exists, additional compaction of the filtered tailings may be required, if achievable, or the facility may require a substantial earthen or rockfill perimeter embankment (similar, perhaps, to a centrelineconstructed dam) to protect against slope failure. For this case, it may be preferable to design a filter plant, and/or tailings conveyance and placement system, to produce a lower moisture content filter cake that will allow for facility construction within tolerable pore pressure limits. If the filtered tailings are not saturated, the deposit may not be susceptible to liquefaction. If an unsaturated filtered tailings deposit exhibits soil suction, as discussed in Robertson et al. (2017), the potential for liquefaction may be further reduced.

\subsection{Underdrainage}

If zones of saturation may develop within the stack, or if the filtered tailings may release pore water once placed, designers should consider incorporating a network of engineered underdrains for the facility. This should be considered even if the tailings are benign and the facility is not constructed with a liner, to mitigate the potential for pore pressure generation and resulting slope stability issues within the stack.

The size and extent of the drainage system should be designed based on calculations of drain down and should include ample redundancy to account for pipe crushing or blockage. The quality of construction of these drains is of considerable importance and the designer should remain involved throughout the process with the construction oversight team.

\section{$4 \quad$ When things go wrong}

As stated previously, things can and do go wrong with filtered tailings facilities. Sometimes, the production moisture content exceeds the design assumptions to a point where the material is difficult to place and compact. On occasion, the field behaviour of a poorly prepared filtered tailings may act in a ductile, almost paste-like manner. Sometimes the placed materials may need in situ improvement or the addition of drains may be necessary.

The observational approach is often usefully employed to counter poor operational results. The key is to employ the approach early. As a reminder, the observational approach is not the same as a 'wait and see' approach. The observational approach means designing for the most likely performance, understanding the alternative performance outcomes, and having remedies in mind to counter them (Peck 1969; Morgenstern 1994).

\subsection{Dealing with excessive moisture}

At some operations, the filter cake is not produced at a low enough moisture content, despite making any possible modifications to the filter plant. Perhaps the best way to contend with excessive moisture in the filter cake is to drive off moisture at the point of deposition.

In arid climates, excessive moisture may be driven off by additional handling of the material. Dozing the filter cake over and over has helped. In some instances, disking or ripping may be beneficial. Any activity that opens more surface area to evaporation can help.

In different environments, alternatives can be employed, and site-specific modifications should be reviewed. Perhaps adding wood chips, saw dust or dry sand to the filter cake would be beneficial. Perhaps amendments such as cement or fly ash could be utilised. The point here is to think beyond the normal boundaries.

\subsection{In situ soil improvement}

There have been filtered tailings facilities that performed so poorly that in situ soil improvement methods were required. Such performance can be first identified through visual observations and may include such things as bulging or slumping of the outer slopes or the appearance of cracks within the facility. 
Piezocone testing (cone penetration tests with pore pressure transducers) can help to reveal the in situ pore pressure regime within a filtered tailings deposit. Piezocone probe locations should be established based on the locations known to be performing poorly, the facility geometry, original topography, etc.

Once the pore pressure regime is established, an appropriate soil improvement technology can be identified. Wick drains have been used to alleviate pore pressures in a clayey filtered tailings operation where some areas of the facility exhibited pore pressures that exceed hydrostatic pressures. This indicates that for the material's properties, the facility was being loaded too rapidly and the filtered tailings was going into a partially undrained loading condition. If a larger footprint could had been available for this facility, the rate of rise (which led to the undrained loading condition) could have been reduced. At this site, a successful continued operation was accomplished using wick drains and careful monitoring of pore pressures (with vibrating wire piezometers installed in the filtered tailings mass), together with added diligence in material placement.

\subsection{Retrofitted drainage}

When caught early enough in a project's life, retrofitted drainage can help to stabilise a poorly-performing facility. Again, the pore pressure regime should be characterised with a series of piezocone tests.

This retrofitted drainage most often takes the form of horizontal strip or blanket drains that extend from the facility perimeter to an area within the facility that should be established to satisfy slope stability requirements. Sizing of the drains should be made with consideration of the permeability of the filtered tailings and the magnitude and distribution of pore pressures within the tailings mass. Such drains should be designed to meet filter and drain criteria and could be sands and gravels or geosynthetic material.

The performance of the drainage system should be monitored using vibrating wire piezometers to establish the successfulness of the installation. Additional drainage can be constructed as the facility is expanded.

\section{Conclusion}

There are no universal tailings management solutions and there is no substitute for careful consideration of project-specific details in developing a tailings management design. An alternatives analysis should be performed to select a preferred tailings management option and demonstrate that potentially advantageous alternatives have not been overlooked. The Guidelines developed by Environment and Climate Change Canada, as referenced in section 2, are a valuable framework for performing such an assessment.

Good tailings facility design practice includes designs that accommodate tailings with varying properties and accounts for potential saturation and the resulting risks of excess pore pressure generation and liquefaction. Further, selecting a target moisture content range for filtered tailings is a key step in the design process. For tailings with increased clay contents, constructability-related criteria present a convenient basis for selecting target moisture contents. Tailings facility designers are reminded that a filtered tailings facility design requires the same level and focus on design as other tailings management options.

\section{Acknowledgement}

I thank my colleagues Josh Rogers, P.E. and Jason M. Cumbers, P.E. for their invaluable input and technical review of this paper and for their helpful comments.

\section{References}

American Society for Testing and Materials 2012a, Standard Test Methods for Laboratory Compaction Characteristics of Soil Using Standard Effort (12 $400 \mathrm{ft}$-lbf/ft3 $\left.\left(600 \mathrm{kN}-\mathrm{m} / \mathrm{m}^{3}\right)\right)$, ASTM International, West Conshohocken, http://www.resolutionmineeis.us/sites/default/files/references/astm-D698.pdf

American Society for Testing and Materials 2012b, Standard Test Methods for Laboratory Compaction Characteristics of Soil Using Modified Effort $\left(56,000 \mathrm{ft}\right.$-lbf/ft3 $\left.\left(2,700 \mathrm{kN}-\mathrm{m} / \mathrm{m}^{3}\right)\right)$, ASTM International, West Conshohocken, https://water.ca.gov/ LegacyFiles/regulations/docs/ASTM\%20D1557\%20Lab\%20Compaction\%20of\%20Soil.pdf 
Caterpillar 2012, Caterpillar Performance Handbook, Caterpillar Inc., Peoria.

Davies, M 2011, 'Filtered dry stacked tailings: the fundamentals', Proceedings of the 15th International Conference on Tailings and Mine Waste, University of British Columbia, Vancouver.

Environment and Climate Change Canada, 2016, Guidelines for the Assessment of Alternatives for Mine Waste Disposal, The Government of Canada, viewed 6 January 2019, https://www.canada.ca/en/environment-climate-change/services/ managing-pollution/publications/guidelines-alternatives-mine-waste-disposal.html

Haile, J \& Brouwer, K n.d., Modified Centreline Construction of Tailings Embankments, viewed 21 November 2018, http://mssi.nrs.gov.bc.ca/1_CIMMountPolley/DOC1535.pdf

Hudbay 2017, Rosemont Project - NI 43-101 Technical Report - Feasibility Study - Updated Mineral Resource, Mineral Reserve and Financial Estimates, Hudbay, Toronto, https://s1.q4cdn.com/305438552/files/doc_downloads/Reports/2017/ RosemontTechReport.pdf

Independent Expert Engineering Investigation and Review Panel 2015, Report on Mount Polley Tailings Storage Facility Breach, https://www.mountpolleyreviewpanel.ca/sites/default/files/report/ReportonMountPolleyTailingsStorageFacilityBreach.pdf

Kerr, T \& Ulrich, BF 2011, 'Tailings impoundments and dams', in P Darling (ed.), SME Mining Engineering Handbook, 3rd edn, Society for Mining, Metallurgy \& Exploration, Inc., Englewood.

M3 2016, Metates Gold-Silver Project - NI 43-101 Technical Report - Updated Preliminary Feasibility Study, http://chesapeakegold.com/downloads/ChesapeakeGold_2016_05_03_142.pdf

Mining Magazine 2017, Goldcorp Trials new EcoTails Technology, viewed 1 June 2018, http://www.miningmagazine.com/ sustainability/news/1264248/goldcorp-trials-ecotails-technology

Morgenstern, NR 1994, 'The observational method in environmental geotechnics', in W Carrier (ed.), Proceedings of the First International Congress on Environmental Geotechnics, Canadian Geotechnical Society, Richmond, pp. 963-976.

Nevada Copper Corp. 2017, Nevada Copper Pumpkin Hollow Project, NI 43-101 Technical Report: Pumpkin Hollow Development Options - Pre-feasibility Study 5,000 tons/day Underground Project; Feasibility Study for a 70,000 tons/day Open Pit/Underground Project, https://www.nevadacopper.com/site/assets/files/5634/ncu-pfs-technical-report-2017_clean180104.pdf

Peck, RB 1969, 'Advantages and limitations of the observational method in applied soil mechanics', Géotechnique, vol. 19, issue 2, pp. 171-187.

Robertson, AM \& Shaw, S 1999, 'A multiple accounts analysis for tailings site selection', Proceedings of the Sudbury 99: Mining and the Environment, vol. 3, pp. 883-892.

Robertson, PK, Viana da Fonseca, A, Ulrich, B \& Coffin, J 2017, 'Characterization of unsaturated mine waste: a case history', Canadian Geotechnical Journal, vol. 54, pp. 1752-1761.

Sivakugan, N \& Das, BM 2010, 'Geotechnical engineering: a practical problem solving approach', J Ross Publishing, Inc., Plantation.

Ulrich, B 2015, 'Innovations in heap leaching and mine waste discussed at 2014 Elko Roundtable', Mining Engineering Magazine, viewed 8 February 2017, http://www.knightpiesold.com/en/assets/File/Article\%20-\%20Innovations\%20in\%20Heap\%20 Leaching\%20and\%20Mine\%20Waste_January\%202015.pdf

Ulrich, B \& Coffin, J 2013, 'Considerations for tailings facility design and operation using filtered tailings', in RJ Jewell, AB Fourie, J Caldwell \& J Pimenta (eds), Proceedings of the 16th International Seminar on Paste and Thickened Tailings, Australian Centre for Geomechanics, Perth, pp. 201-210.

Ulrich, B \& Kerr, T 2011, 'Elko Roundtable 2011: high-density tailings, paste and filtered tailings', Mining Engineering Magazine, https://www.knightpiesold.com/en/assets/File/Article\%20-\%20Elko\%20Roundtable\%202011_November\%202011.pdf

Vardanega, PJ \& Haigh, SK 2014, 'The undrained strength - liquidity index relationship', Canadian Geotechnical Journal, vol. 51, pp. 1073-1086.

Watson, A 2010, Alternative Tailing Disposal - Fact and Fiction, Paste Tailings Management, Supplement to International Mining.

Wilson, GW \& Robertson, AM 2015, 'The value of failure', Geotechnical News, vol. 33, issue 2. 
